\title{
Faktor-faktor yang Berhubungan dengan Kejadian Neglected Fracture pada Pasien di RSUP Prof Dr. R. D. Kandou Manado pada Periode Januari-Desember 2018
}

\author{
Hartini F. Galo, ${ }^{1}$ Rangga Rawung, ${ }^{2}$ Eko Prasetyo ${ }^{2}$
}

${ }^{1}$ Program Studi Pendidikan Dokter Fakultas Kedokteran Universitas Sam Ratulangi Manado

${ }^{2}$ Bagian Ilmu Bedah Fakultas Kedokteran Universitas Sam Ratulangi-RSUP Prof. Dr. R. D.

Kandou Manado

Email: hartinigalo1404@gmail.com

\begin{abstract}
Inproper and delayed management of fracture could cause neglected fracture (NF) with or without dislocation resulting in worse condition and disability. The incidence of NF is high enough worldwide, especially in developing countries such as Indonesia. Albeit, there is no accurate data of NF incidence, especially in Manado. This study was aimed to determine the factors related to NF incidence. This was an observational and analytical study with a retrospective approach and a cross-sectional design. In this study, we used medical record data of fracture patients with and without NF form January 1 to December 31, 2018 at Prof. Dr. R. D. Kandou Hospital Manado. The results showed that of five factors analyzed by using chisquare test, two factors were correlated to NF incidence $(\mathrm{p}<0.05)$ which were age and sex, meanwhile educational status, fracture location, and patient's home address were not correlated to NF incidence ( $p>0.05$ ). In conclusion, there were significant relationships between age and sex and the incidence of negleted fracture.
\end{abstract}

Keywords: neglected fracture

\begin{abstract}
Abstrak: Penanganan fraktur yang tidak tepat dan cepat akan menimbulkan kejadian neglected fracture $\mathrm{NF}$ dengan atau tanpa dislokasi yang berakibat memburuknya kondisi atau bahkan kecacatan. Data pasti mengenai kejadian NF khususnya di Manado belum ada. Penelitian ini bertujuan untuk mengetahui factor-faktor yang berhubungan dengan kejadian NF. Jenis penelitian ialah observasional-analitik dengan pendekatan retrospektif dan desain potong lintang menggunakan data rekam medik pasien fraktur yang mengalami NF dan nonNF pada 1 Januari-31 Desember 2018 di RSUP Prof. Dr. R. D. Kandou Manado. Hasil penelitian menunjukkan dari lima faktor yang diteliti menggunakan chi-square test didapatkan bahwa faktor yang berhubungan dengan kejadian $\mathrm{NF}(\mathrm{p}<0,05)$ yaitu usia dan jenis kelamin, sedangkan faktor status pendidikan, lokasi fraktur, dan alamat tempat tinggal pasien tidak berhubungan dengan kejadian NF ( $>0,05)$. Simpulan penelitian ini ialah terdapat dua faktor yang berhubungan bermakna dengan kejadian NF yaitu usia dan jenis kelamin.
\end{abstract}

Kata kunci: neglected fracture

\section{PENDAHULUAN}

Trauma merupakan salah satu penyumbang angka mortalitas dan morbiditas. World Health Organization (WHO) melaporkan bahwa trauma termasuk ke dalam 10 besar penyebab terbanyak kematian di dunia. Menurut Komisi Trauma US di
Amerika, trauma merupakan penyebab utama kematian pada usia produktif, dan insiden cedera melibatkan ekstremitas yang paling sering terjadi. ${ }^{1}$ Studi di Singapura melaporkan $45 \%$ dari kasus trauma mengenai ekstremitas, dan kecelakaan lalu lintas merupakan penyebab paling sering 
terjadinya kasus-kasus trauma serta penyebab utama kematian dan kecacatan. ${ }^{2}$ Berdasarkan hal tersebut, sangat diperlukan penguasaan terhadap penanganan trauma khususnya patah tulang/fraktur.

Penguasaan terhadap prinsip-prinsip penanganan trauma, terbukti menurunkan angka mortalitas dan morbiditas akibat trauma. ${ }^{1}$ Berbagai studi melaporkan bahwa pusat layanan kesehatan yang menerapkan prinsip-prinsip penanganan trauma berhasil menurunkan angka mortalitas dan morbidditas akibat trauma hingga $90 \% .^{3}$ Namun, hal ini tidak cukup dapat dilaksanakan pada pasien trauma terutama di Negara-negara berkembang. Studi melaporkan berbagai faktor telah memengaruhi kurang optimalnya penanganan trauma di negara berkembang. ${ }^{4}$ Hal tersebut menimbulkan kejadian neglected trauma, yang akan meningkatkan komplikasi, menurunkan kualitas hidup, mengurangi kemampuan produksi, dan menjadi beban ekonomi sebuah negara. ${ }^{5}$ Salah satu studi yang dilakukan WHO menyatakan bahwa kasus-kasus trauma di negara berkembang telah meningkat hampir 20\% dalam 10 tahun terakhir, dan diperkirakan menghabiskan kurang lebih 500 biliun dolar US dalam penanganannya. ${ }^{1}$

Salah satu akibat dari trauma yaitu fraktur atau patah tulang. Neglected fracture/NF dengan atau tanpa dislokasi adalah suatu fraktur yang tidak ditangani atau ditangani dengan tidak semestinya sehingga menghasilkan keadaan keterlambatan dalam penanganan, atau kondisi yang lebih buruk dan bahkan kecacatan. ${ }^{6}$

Angka pasti jumlah kasus NF di negara berkembang tidak diketahui karena masih minimnya studi. Salah satu studi yang dilakukan di India menyatakan bahwa beberapa faktor-faktor yang memengaruhi terjadinya kasus-kasus NF, antara lain adanya pemahaman dan kesadaran untuk hidup sehat yang rendah, minimnya sarana prasarana layanan kesehatan, akses mendapatkan pelayanan kesehatan yang sulit, jumlah penduduk, urbanisasi, asuransi, kultur, kepercayaan, dan sosial budaya. ${ }^{4,7}$

Di Indonesia, studi mengenai kasus NF masih minim; dua diantaranya yaitu studi yang dilakukan oleh $\mathrm{Ayu}^{8}$ di Medan dan Utami $^{9}$ di Bandar Lampung. Ayu ${ }^{8}$ menyatakan bahwa karakteristik pasien NF yaitu lebih banyak dijumpai pada laki-laki, usia produktif, berasal dari luar kota Medan, tingkat pendidikan rendah, sebelumnya mendapat perawatan di dukun patah, dan lokasi tersering NF yaitu pada tulang femur. Penelitian yang dilakukan oleh Utami $^{9}$ di Bandar Lampung mendapatkan faktor-faktor yang berpengaruh terhadap kejadian NF di Kota Bandar Lampung di antaranya tingkat pendidikan, budaya, dan pengetahuan pasien, namun tingkat ekonomi dan keterjangkauan pelayanan kesehatan tidak berhubungan dengan kejadian NF.

Di Manado, penelitian mengenai NF masih sangat minim dan data mengenai pasien NF belum diketahui secara pasti, namun kenyataannya kasus ini dapat menyebabkan hal yang sangat serius seperti kecacatan. Berdasarkan hal tersebut peneliti tertarik untuk melakukan penelitian terkait faktor-faktor yang berhubungan dengan kejadian neglected fracture pada pasien di RSUP Prof. Dr. R. D. Kandou Manado dengan periode waktu dari bulan Januari hingga Desember 2018.

\section{METODE PENELITIAN}

Jenis penelitian yang digunakan dalam penelitian ini ialah observasional-analitik dengan pendekatan retrospektif dan desain potong lintang. Data penelitian diambil dari status rekam medik pasien fraktur yang mengalami NF ataupun non-NF dalam periode waktu tertentu. Sampel penelitian ialah seluruh pasien fraktur yang mengalami NF ataupun non-NF yang memiliki informasi data lengkap berupa jenis kelamin, usia, diagnosis, alamat tempat tinggal, dan status pendidikan pasien, pada periode 1 Januari-31 Desember 2018 yang memenuhi kriteria inklusi.

Variabel bebas dalam penelitian ini yaitu jenis kelamin, usia, lokasi fraktur, status pendidikan, dan alamat tempat tinggal pasien sedangkan variabel terikat yaitu NF. Uji statistik chi-square digunakan untuk mengetahui ada tidaknya hu- 
bungan antara variabel bebas dengan terikat. Uji regresi logistik bergamda digunakan untuk mengetahui faktor dominan (variabel bebas) yang memengaruhi variabel terikat.

\section{HASIL PENELITIAN}

Pada penelitian yang dilakukan di RSUP Prof. Dr. R. D. Kandou Manado untuk periode Januari-Desember 2018, didapatkan 73 pasien yang mengalami fraktur baik NF ataupun non-NF yang memenuhi kriteria inklusi.

Tabel 1 memperlihatkan karakteristik pasien dengan beberapa variabel penelitian, yang meliputi usia, jenis kelamin, lokasi fraktur, status pendidikan, dan alamat tempat tinggal.

Tabel 2 memperlihatkan distribusi pasien menurut jenis kelamin. Jumlah pasien laki-laki dengan NF jauh lebih tinggi daripada pasien perempuan, sedangkan yang non-NF hampir sama banyak untuk kedua jenis kelamin.
Tabel 3 memperlihatkan distribusi pasien menurut lokasi fraktur dan kejadian NF. Untuk pasien NF dan non-NF, lokasi fraktur terbanyak pada ekstremitas bawah.

Tabel 4 memperlihatkan distribusi pasien menurut pendidikan dan kejadian NF. Kasus fraktur pada NF dan non-NF terbanyak ditemukan pada pasien yang tamat SMA.

Tabel 5 memperlihatkan distribusi alamat tempat tinggal pasien dan yang terbanyak ialah dari luar Manado untuk kedua jenis fraktur.

Tabel 6 memperlihatkan distribusi pasien menurut usia dan kejadian NF. Untuk pasien NF, terbanyak ditemukan pada usia dewasa sedangkan untuk pasien non-NF terbanyak ditemukan pada pasien lansia.

Tabel 7 memperlihatkan hasil uji regresi logistik berganda faktor-faktor yang berhubungan dengan kejadian NF. Hasil analisis hubungan usia menurut kejadian NF mendapatkan nilai $\mathrm{p}=0,001 \leq 0,05$ yang menunjukkan adanya hubungan bermakna antara usia dengan kejadian NF.

Tabel 1. Karakteristik pasien dengan beberapa variabel pada penelitian, dalam $\mu \pm S D$ dan $\mathrm{n}(\%)$

\begin{tabular}{lcccc}
\hline \multicolumn{1}{c}{ Karakteristik } & $\begin{array}{c}\text { Total } \\
(\mathrm{N}=73)\end{array}$ & $\begin{array}{c}\mathbf{N F} \\
(\mathrm{n}=32)\end{array}$ & $\begin{array}{c}\text { Don-NF } \\
(\mathrm{n}=41)\end{array}$ & $\mathbf{p}^{a}$ \\
\hline $\begin{array}{l}\text { Usia } \\
\text { Jenis kelamin }\end{array}$ & $40,3 \pm 23,6$ & $29,0 \pm 16,1$ & $48,6 \pm 24,6$ & $0,001^{*}$ \\
$\quad$ Laki-laki & & & & \\
$\quad$ Perempuan & $43(59)$ & $23(32)$ & $20(49)$ & $0,049^{*}$ \\
Lokasi fraktur & $30(41)$ & $9(12)$ & $21(29)$ & \\
$\quad$ Kepala & & & & \\
$\quad$ Badan & $0(0)$ & $0(0)$ & $0(0)$ & 0,635 \\
$\quad$ Ekstremitas atas & $9(12)$ & $4(44)$ & $5(56)$ & \\
$\quad$ Ekstremitas bawah & $13(18)$ & $7(54)$ & $6(46)$ & \\
Status pendidikan & $51(70)$ & $21(41)$ & $30(59)$ & \\
$\quad$ Tidak tamat SMA & & & & \\
$\quad$ Tamat SMA & $20(27)$ & $10(50)$ & $10(50)$ & 0,515 \\
Alamat tempat tinggal & $53(73)$ & $22(42)$ & $31(59)$ & \\
$\quad$ Luar Manado & & & & \\
$\quad$ Manado & $45(61)$ & $23(51)$ & $22(49)$ & 0,115 \\
\hline
\end{tabular}

Keterangan: SD standar deviasi, usia. ${ }^{\mathrm{a}}$ Uji chi-square pada variabel kategorik dan uji $t$ pada variabel numerik; * nilai p bermakna. 
36 e-CliniC, Volume 8, Nomor 1, Januari-Juni 2020, hlm. 33-40

Tabel 2. Distribusi pasien menurut jenis kelamin dan kejadian NF

\begin{tabular}{lcc}
\hline Jenis kelamin & \multicolumn{2}{c}{ Diagnosis } \\
& Non-NF & NF \\
\hline Laki-laki & $20(48,8 \%)$ & $23(71,9 \%)$ \\
Perempuan & $21(51,2 \%)$ & $9(28,1 \%)$ \\
Total & $41(56,2 \%)$ & $32(43,8 \%)$ \\
\hline
\end{tabular}

Tabel 3. Distribusi pasien menurut lokasi fraktur dan kejadian NF

\begin{tabular}{lcc}
\hline Lokasi fraktur & \multicolumn{2}{c}{ Diagnosis } \\
& Non-NF & NF \\
\hline Kepala & $0(0,0 \%)$ & $0(0,0 \%)$ \\
Badan & $5(55,6 \%)$ & $4(44,4 \%)$ \\
Ekstremitas atas & $6(46,2 \%)$ & $7(53,8 \%)$ \\
Ekstremitas & $30(58,8 \%)$ & $21(41,2 \%)$ \\
bawah & & \\
Total & $41(56,2 \%)$ & $32(43,8 \%)$ \\
\hline
\end{tabular}

Tabel 4. Distribusi pasien menurut status pendidikan dan kejadian NF

\begin{tabular}{lcc}
\hline Status pendidkan & \multicolumn{2}{c}{ Diagnosis } \\
& Non-NF & NF \\
\hline Tidak tamat SMA & $10(50,0 \%)$ & $10(50,0 \%)$ \\
Tamat SMA & $31(58,5 \%)$ & $22(41,5 \%)$ \\
Total & $41(56,2 \%)$ & $32(43,8 \%)$ \\
\hline
\end{tabular}

Tabel 5. Distribusi pasien menurut alamat tempat tinggal dan kejadian NF

\begin{tabular}{ccc}
\hline Alamat & \multicolumn{2}{c}{ Diagnosis } \\
& Non-NF & NF \\
\hline Luar Manado & $22(48,9 \%)$ & $23(51,1 \%)$ \\
Manado & $19(67,9 \%)$ & $9(32,1 \%)$ \\
Total & $41(56,2 \%)$ & $32(43,8 \%)$ \\
\hline
\end{tabular}

Tabel 6. Distribusi pasien menurut usia dan kejadian NF

\begin{tabular}{lcccc}
\hline Diagonsis & \multicolumn{3}{c}{ Usia } & Total \\
& $\begin{array}{c}\text { Anak-anak } \\
(\leq 18 \text { tahun })\end{array}$ & $\begin{array}{c}\text { Dewasa } \\
(19-59 \text { tahun })\end{array}$ & $\begin{array}{c}\text { Lansia } \\
(\geq 60 \text { tahun })\end{array}$ & \\
\hline NF & $8(27,0 \%)$ & $19(63,0 \%)$ & $3(10,0 \%)$ & $30(100,0 \%)$ \\
Non NF & $6(15,0 \%)$ & $16(40,0 \%)$ & $18(45,0 \%)$ & $40(100,0 \%)$ \\
\hline
\end{tabular}

Tabel 7. Hasil uji regresi logistik berganda faktor-faktor yang berhubungan dengan kejadian NF

\begin{tabular}{lcccc}
\hline \multicolumn{1}{c}{ Variabel } & $\begin{array}{c}\text { Kejadian NF } \\
\text { Model Bivariant Exps (B) }\end{array}$ & Wald $^{\mathbf{b}}$ & Nilai p & 95\% Cl \\
& 0,957 & 11,369 & 0,001 & $0,933-0,982$ \\
Usia & 2,683 & 3,863 & 0,049 & $1,003-7,180$ \\
Jenis kelamin & 0,853 & 0,225 & 0,635 & $0,442-1,646$ \\
Lokasi fraktur & 1,409 & 0,423 & 0,515 & $0,253-1,994$ \\
Status pendidikan & 2,207 & 2.480 & 0,115 & $0,169-1,124$ \\
Alamat tempat tinggal & & &
\end{tabular}

$\mathrm{CI}$, confidence interval $;{ }^{\mathrm{a}}$ Analisis bivariant, odds ratio; ${ }^{\mathrm{b}} \mathrm{Wald}$, kekuatan masing-masing hubungan variabel 
Odd ratio yang dihasilkan sebesar 0,957. Hasil analisis multivarian mendapatkan nilai Wald 11,369 yang berarti terdapat hubungan antara usia dengan kejadian NF yang paling kuat dibandingkan keempat variabel lainnya.

Hasil analisis hubungan jenis kelamin menurut kejadian NF mendapatkan nilai $\mathrm{p}=0,049 \leq 0,05$, yang menunjukkan adanya hubungan bermakna antara jenis kelamin dengan kejadian NF. Odd ratio yang dihasilkan sebesar 2,683, yang berarti bahwa laki-laki dua kali berisiko mengalami NF berdasarkan insidensi yang ditemukan.

Hasil analisis hubungan lokasi fraktur dengan kejadian NF mendapatkan nilai $\mathrm{p}=0,635 \geq 0,05$, yang menunjukkan tidak terdapat hubungan bermakna antara lokasi fraktur dengan kejadian NF.

Hasil analisis hubungan status pendidikan dengan kejadian NF mendapatkan nilai $\mathrm{p}=0,515 \geq 0,05$, yang menunjukkan tidak terdapat hubungan bermakna antara status pendidikan dengan kejadian NF.

Hasil analisis hubungan alamat tempat tinggal pasien dengan kejadian NF mendapatkan nilai $\mathrm{p}=0,115 \geq 0,05$, yang menunjukkan tidak terdapat hubungan bermakna antara alamat tempat tinggal dengan kejadian NF.

\section{BAHASAN}

Pada penelitian ini didapatkan jumlah pasien fraktur sebanyak 73 pasien, kejadian non-NF lebih banyak terjadi pada pasien frak tur dibandingkan kejadian NF. Jumlah tersebut termasuk dalam jumlah yang besar dan hampir menyamai jumlah penderita non-NF pada pasien fraktur dan perlu mendapat perhatian yang khusus. Hasil ini sesuai penelitian yang dilakukan oleh $\mathrm{Ayu}^{8}$ di Medan. Dengan adanya data pasien NF di Manado khususnya di RSUP Prof. Dr. R. D. Kandou, hasil penelitian ini belum dapat dikatakan mengalami peningkatan oleh karena tidak ada data sebelumnya mengenai kejadian NF yang dapat dijadikan sebagai pembanding kejadian NF yang terjadi pada tahun 2018 di RSUP Prof. Dr. R. D. Kandou Manado.
Berdasarkan data kejadian NF menurut jenis kelamin, terdapat hubungan antara jenis kelamin dengan kejadian NF, laki-laki dua kali lebih berisiko mengalami NF dibandingkan perempuan berdasarkan data insidensi. Pada pasien yang berjenis kelamin laki-laki sebanyak $23 \quad(72,0 \%)$ orang mengalami NF, dibandingkan perempuan. Hasil penelitian ini sesuai dengan penelitian yang dilakukan oleh $\mathrm{Ayu}^{8}$ yang mendapatkan kejadian NF lebih banyak dialami oleh laki-laki dibandingkan perempuan. Hal ini dapat disebabkan karena, meningkatnya kejadian fraktur sehingga kejadian NF pun ikut meningkat, dan penyebab fraktur terbanyak yaitu kecelakaan lalu lintas.

Berdasarkan beberapa penelitian salah satunya dilakukan oleh Riandini et $\mathrm{al}^{10} \mathrm{di}$ Padang yang menyatakan bahwa distribusi korban kecelakaan lalu lintas didominasi jenis kelamin laki-laki. Hal ini disebabkan laki-laki lebih banyak beraktivitas di luar ruangan sehingga lebih berisiko mengalami fraktur termasuk NF. Dengan meningkatnya kecelakaan lalu lintas, maka kejadian fraktur juga meningkat dan bisa saja diikuti dengan meningkatnya kejadian NF, tetapi perlu juga diperhatikan faktor lainnya dalam hal ini proses remodeling tulang yang mengalami fraktur. Pernyataan Riandini juga didukung oleh beberapa penelitian, di antaranya ialah penelitian yang dilakukan oleh Gill ${ }^{11}$ dan oleh Noorisa et $\mathrm{al}^{12}$ yaitu pasien fraktur akibat kecelakaan lalu lintas lebih didominasi oleh laki-laki dibandingkan perempuan. Lakilaki dua kali lebih berisiko mengalami NF dibandingkan perempuan dikarenakan insidensi fraktur yang meningkat dan lebih banyak dialami oleh laki-laki, sehingga lebih memungkinkan terjadinya NF. Selain itu juga dipengaruhi oleh perilaku mencari pengobatan.

Menurut golongan usia, kejadian NF memiliki hubungan bermakna dengan usia. Hal ini dapat dilihat pada kejadian NF lebih banyak dialami oleh pasien usia dewasa (19-59 tahun), kemudian diikuti oleh usia anak-anak ( $\leq 18$ tahun) sedangkan usia yang paling sedikit mengalami NF yaitu lansia 
( $\geq 60$ tahun). Hal ini selaras dengan penelitian yang dilakukan oleh $\mathrm{Ayu}^{8}$ di Medan yang mendapatkan golongan usia dewasa lebih dominan mengalami NF dibandingkan golongan usia lainnya. ${ }^{8}$ Hal ini dapat disebabkan karena golongan usia dewasa merupakan golongan usia produktif yang mempunyai mobilitas lebih banyak sehingga lebih memungkinkan terjadinya fraktur yang dapat memicu terjadinya $\mathrm{NF}$ dibandingkan golongan usia lainnya. Hal ini dibuktikan juga oleh penelitian yang dilakukan oleh Zai et al $^{13}$ di Manado yang melaporkan bahwa usia dewasa lebih dominan mengalami trauma, sehingga bisa saja menyebabkan terjadinya NF.

Kejadian NF pada pasien lansia lebih sedikit terjadi dibandingkan golongan usia lainnya. Pernyataan sebelumnya mengenai $\mathrm{NF}$, yaitu jika kejadian fraktur meningkat maka kejadian NF turut meningkat. Berbeda halnya pada golongan usia lansia, osteoporosis merupakan salah satu penyebab tingginya insiden fraktur tulang, khususnya pada perempuan usia lebih dari 50 tahun dibanding usia lainnya. Hal ini disebabkan oleh beberapa faktor lainnya dalam hal ini faktor remodeling tulang. Pada usia lansia tepatnya pada usia 50-60 tahun resorpsi tulang lebih sering terjadi dibandingkan remodeling tulang akibat meningkatnya aktivitas osteoklas dan menurunnya aktivitas osteoblas. ${ }^{14}$ Proses remodeling tulang lebih cepat terjadi pada golongan usia yang lebih muda.

Golongan usia anak-anak ( $\leq 18$ tahun) menempati urutan kedua golongan usia terbanyak yang mengalami NF. Pada anakanak yang mengalami fraktur, proses remodeling tulang membutuhkan waktu yang lebih singkat dibandingkan orang dewasa, karena aktivitas osteoblas lebih tinggi dibandingkan daripada orang dewasa. ${ }^{15,16}$ Kejadian NF terjadi karena penanganan yang tidak tepat dalam hal imobilisasi dan waktu penanganannya yang lama pada pasien fraktur khususnya anak-anak, sehingga menyebabkan terjadinya pembentukan kalus permanen. Usia memengaruhi kejadian NF dikarenakan pada usia tertentu insiden kejadian fraktur meningkat, dan dipengaruhi oleh faktor remodeling tulang dalam hal ini hormon serta aktivitas fisik yang berlebihan yang mempercepat proses remodeling tulang.

Ekstremitas bawah merupakan lokasi tersering ditemukannya NF. Hal ini sesuai dengan penelitian yang dilakukan oleh $\mathrm{Ayu}^{8}$ yang mendapatkan lokasi tulang yang paling sering mengalami NF yaitu ekstremitas bawah tepatnya pada daerah femur. ${ }^{8}$ Namun, tidak terdapat hubungan antara lokasi faktur dengan kejadian NF pada penelitian ini. Lokasi fraktur terbanyak pada pasien NF bisa saja disebabkan karena kejadian fraktur dengan lokasi tersering terjadinya fraktur yaitu pada ektremitas bawah. Hal ini dibuktikan oleh beberapa penelitian salah satunya yang dilakukan oleh Gill yang menyatakan bahwa ekstremitas bawah (femur dan tibia) merupakan lokasi tersering terjadinya fraktur diikuti oleh ekstremitas atas (radius dan ulna). ${ }^{11}$ Hasil penelitian yang dilakukan oleh Gill sejalan dengan yang dilakukan oleh Meling et $\mathrm{al}^{17}$ di Norwegia.

Hasil penelitian ini mendapatkan tidak adanya hubungan status pendidikan dengan kejadian NF. Hasil ini selaras dengan penelitian yang dilakukan oleh Rambe ${ }^{18}$ di Medan yang menyatakan tidak terdapat hubungan antara status pendidikan dengan kejadian NF. Hasil penelitian ini tidak sejalan dengan penelitian yang dilakukan Utami $^{9}$ di Lampung (2016) yang menyatakan terdapat hubungan antara status pendidikan dengan kejadian NF dan kejadian NF lebih banyak dialami pada pasien yang memiliki status pendidikan tidak tamat SMP dibanding tamat SMP. Selain itu penelitian yang dilakukan oleh Kristina et al $^{19}$ mendukung hasil penelitian Utami $^{9}$ di Lampung yaitu tingkat pendidikan berhubungan dengan perilaku mencari pengobatan sendiri dan merupakan faktor dominan. Perbedaan hasil dengan beberapa penelitian sebelumnya dapat saja disebabkan oleh karena data yang didapatkan peneliti tidak cukup banyak, kurang lengkapnya data, metode pengambilan data sampel yang berbeda dengan penelitianpenelitian sebelumnya yang menggunakan 
kuisoner/wawancara untuk mengetahui pengetahuan pasien mengenai fraktur serta standar kriteria variabel yang digunakan berbeda.

Hasil penelitian ini menunjukkan bahwa tidak terdapat hubungan antara alamat tempat tinggal dengan kejadian NF. Hal ini didukung oleh penelitian Utami ${ }^{9}$ di Lampung Hasil penelitian tersebut juga didukung dengan penelitian yang dilakukan oleh Sari et $\mathrm{al}^{20}$ di Semarang yang menyatakan tidak terdapat hubungan bermakna antara tingkat pendidikan dengan keterlambatan berobat pada pasien patah tulang.

Pasien fraktur yang memiliki alamat tempat tinggal di luar Kota Manado lebih banyak mengalami NF dibandingkan yang memiliki alamat tempat tinggal di Kota Manado, namun hal ini tidak berbeda bermakna. Sama halnya dengan penelitian yang dilakukan oleh $\mathrm{Ayu}^{8}$ dan juga mendukung teori mengenai faktor-faktor perilaku sehat dimana salah satunya yaitu ketersedian sarana dan prasarana kesehatan. Perbedaan hasil dengan penelitian sebelumnya atau bahkan teori yang ada, bisa saja dikarenakan metode pengambilan data sampel yang kurang spesifik.

Dari keseluruhan faktor yang telah diteliti hanya terdapat dua faktor yang berhubungan dengan kejadian NF yaitu usia dan jenis kelamin. Hubungan yang paling kuat menurut faktor yang ada yaitu hubungan antara usia dengan kejadian NF.

Keterbatasan penelitian ini ialah jumlah sampel yang kurang akibat banyak data rekam medik yang tidak lengkap dan beberapa data rekam medik tidak ditemukan pada saat penelitian. Selain itu waktu penelitian sangat singkat dan metode pengambilan data pasien yang digunakan tidak spesifik.

\section{SIMPULAN}

Pada pasien fraktur yang mengalami NF dan non-NF di RSUP Prof. Dr. R. D. Kandou Manado periode 1 Januari - 31 Desember 2018 didapatkan bahwa usia dan jenis kelamin berhubungan bermakna dengan kejadian NF. Tidak didapatkan hubungan antara status pendidikan, lokasi fraktur, dan alamat tempat tinggal pasien dengan kejadian NF.

Bagi pasien dan masyarakat, agar dapat menghindari fraktur sehingga mengurangi kemungkinan mengalami kejadian NF dan bagi pasien fraktur agar segera mengunjungi pusat pelayanan kesehatan terdekat untuk mendapatkan penanganan fraktur yang tepat dan cepat sehingga terhindar dari kejadian NF. Bagi peneliti selanjutnya, agar menambah lebih banyak sampel dan variabel yang belum diteliti seperti jenis asuransi pasien, pekerjaan, asal suku pasien dll. Peneliti juga menyarankan bagi peneliti selanjutnya agar menggunakan metode pengambilan data pasien yang lebih spesifik. Bagi tenaga medis, agar segera melakukan pencegahan terhadap kejadian NF terutama faktor-faktor yang berhubungan dengan kejadian NF yaitu usia dan jenis kelamin. Bagi instansi kesehatan terkait dalam hal ini penyedia layanan kesehatan, agar meratakan pelayanan kesehatan di setiap daerah khususnya di Sulawesi Utara dalam hal penanganan fraktur baik dalam hal sarana dan prasarana layanan kesehatan yang ada dan memberikan informasi kepada seluruh masyarakat memalui program-program kesehatan yang ada, mengenai faktor-faktor yang berhubungan dengan kejadian NF.

\section{Konflik Kepentingan}

Penulis menyatakan tidak terdapat konflik kepentingan dalam studi ini.

\section{DAFTAR PUSTAKA}

1. Moore K. Injury prevention and trauma mortality. J Emerg Nurs. 2016;42(5): 457-8.

2. Wui LW, Shaun GE, Ramalingam G, Wai KMS. Epidemiology of trauma in an acute care hospital in Singapore. J Emerg Trauma Shock. 2014;7(3):174-9.

3. Byun CS, Park IH, Oh JH, Bae KS, Lee KH, Lee E. Epidemiology of trauma patients and analysis of 268 mortality cases: Trends of a single center in Korea. Yonsei Med J. 2015;56(1):220-6.

4. Nantulya VM. The neglected epidemic: road traffic injuries in developing countries. BMJ. 2002;324(7346):1139-41. 
5. Depkes. Penyakit tidak menular penyebab kematian terbanyak di Indonesia. Depkes 2009. 2016:1-2. Available from: http://www.depkes.go.id/article/ view/1637/penyakit-tidak-menularptm-penyebab-kematian-terbanyak-diindonesia.html.

6. Solomon L. Apley's System of Orthopedic's and Fracture's (9th ed). Boca Raton: CRC press; 2013.

7. Gavaskar AS, Kumar R. Open interlocking nailing and bone grafting for neglected femoral shaft fractures. J Orthopedic Surgery (Hong Kong). 2010;18(1):459.

8. Ayu O. Karakteristik penderita neglected fractures yang dirawat di RSUP $\mathrm{H}$. Adam Malik Medan periode Januari 2009-Desember 2010. Majalah Kedokteran Nusantara. 2017;47(2): 68-71.

9. Utami M. Faktor-faktor yang berhubungan dengan kejadian neglected fracture pada pasien Rumah Sakit Umum Daerah A. Dadi Tjokrodipo Bandar Lampung [Skripsi]. Bandar Lampung: Universitas Lampung; 2016.

10. Riadini IL, Susanti R., Yanis A. Gambaran luka korban kecelakaan lalu lintas yang dilakukan pemeriksaan di RSUP Dr. M. Djamil Padang. Jurnal Kesehatan Andalas. 2015;4(2):502-508.

11. Gill UN. Epidemiology of orthopaedics fractures in under-developed country due to trauma, a retrospective study. Departement of Orthopedic. Lahore General Hospital. 2014:64-66. Available from: http://jpoa.org.pk/ index.php/upload/article/view/84.

12. Noorisa R. The characteristic of patient with femoral fracture in depertement of orthopaedic and traumatology RSUD Dr. Soetomo Surabaya 2013-2016. Journal of Orthopaedi \& Traumatologi Surabaya. 2017;6(1):200.
13. Zai PC, Wagiu A, Rawung R. Profil pasien trauma akibat kecelakaan lalu lintas yang dirawat di Instalasi Rawat Darurat Bedah RSUP Prof. Dr. R. D. Kandou Manado Periode 1 Januari - 31 Desember 2017. e-CliniC. 2018;6(2): 94-99.

14. Lauralee S. Kelenjar endokrin perifer. In: Introduction to Human Physiology (8th ed). Jakarta: EGC, 2013; p. 760-1.

15. Hall J. Hormon paratiroid, kalsitonin, metabolisme kalsium dan fosfat, vitamin D, tulang dan gigi. In: Guyton dan Hall Buku Ajar Fisiologi Kedokteran. Singapore: Saunder Elsevier, 2011; p. 960-1.

16. Lauralee S. Prinsip-prinsip endokrinologi kelenjar endokrin sentral. In: Introduction to Human Physiology (8th ed). Belmont: Brooks/Cole Cengage Learning; 2013:707-9.

17. Meling T, Harboe K, Søreide K. Incidence of traumatic long-bone fractures requiring in-hospital management: A prospective age-and gender-specific analysis of 4890 fractures. Injury. 2009;40(11): 1212-9.

18. Rambe SH. Faktor-faktor yang berhubungan dengan keterlambatan berobat pada pasien patah tulang di RSU Piringandi Medan. Jurnal Keperawatan Flora. 2016; IX(1):66-80.

19. Kristina SA, Prabandanri YS, Sudjaswadi R. Perilaku pengobatan sendiri yang rasional pada masyarakat. Berita Kedokteran Masyarakat. 2007;23(4): 176-83.

20. Sari AP, Priambodo A, Pramono D, Yudhanto E, Budijitno S. Faktor-faktor yang berhubungan dengan keterlambatan berobat pada pasien patah tulang yang menggunakan sistem pembiayaan Jamkesmas (Studi Kasus di RS Dr. Kariadi Semarang) [Skripsi]; 2012. 